\title{
Socioeconomic Inequalities in Common Mental Disorders: A Systematic Review
}

\author{
Article by Edna Chirwa Simwinga \\ Ph.D Psychology, Texila American University \\ Email: ecsimwinga@gmail.com
}

\begin{abstract}
Low socioeconomic status (SES) is generally associated with high medical morbidity, and poorer access to health care. A number of studies have investigated the relationship between SES and common mental disorders with differing results. Therefore, the author conducted a systemic review to evaluate such an association. The review included 17 studies. Socioeconomic inequality in common mental disorders is mixed and varies according to the approach mental disorder is accessed, to the definition and measurement scales of SES, and to background characteristics such as region and time. However, the analysis found convincing evidence for socioeconomic inequality in common mental disorders. Policies for tackling inequality in common mental disorders are necessary, particularly in relationship with the course of the disorders.
\end{abstract}

Keywords: Mental disorders, SES, depression, anxiety, level of education

\section{Introduction}

Low socioeconomic status (SES) is generally associated with high medical morbidity and poor access to health care. This situation extends to mental disorder as well. In countries where epidemiologic studies have been conducted and compared, the group in the lowest level of education had a higher prevalence of mental disorder morbidity (Andrade et al. 2000). Lower SES group have higher risk factors such as poorer coping styles, stress exposure, ongoing life events, and weaker social support among others compared to groups in higher SES (Turner and Lloyd, 1999). Even in cases where both groups suffer mental disorder also it has been found to be unequally spread. For example, even with the same severity level, lower SES groups tend to suffer more impairment (Bebbington, et al. 2000) and have a poorer prognosis (Weich \& Lewis, 1998). In places where the government does not provide sufficient welfare support, people in lower SES groups tend to have lower access to health care in general (Katz, et al 1997) and they are were less expected to have access to expert mental care (Algeria et al. 2000).

Strong empirically based studies show a link between social conditions and disease and based on these studies, the theory holds that disease risk at the individual level should be studied in the context of the wider social conditions that leaves individuals to health compromising circumstances. Therefore, well-being is hypothesized to be a consequence of access to social as well as material resources.

In a study review by Dohrenwend \& Dohrenwend (1969) that included all types of mental disorders, 17 studies of 20 studies evaluated all types showed higher rates of global medical disorder among the lowest SES group. However, upon examination of the early psychopathologic epidemiologic studies Dohrenwend (1998) found that most studies had three main methodological weaknesses. Firstly, most studies only enrolled participants who were patients, consequently making research results vulnerable to variations in the helpseeking behavior and referral process (Holzer, et. al.1986). Then secondly, most studies conceptualized mental disorder with poor classification and criteria that were inadequate for setting the threshold of mental disorders (Dohrenwend 1998; Anthony, Eaton \& Henderson (1995). And thirdly, they employed symptom-screening tools that were unsatisfactorily specific, because they mixed a wide range of psycho-physiologic disorders as well as true 
Texila International Journal of Psychology

Volume 1, Issue 2, Dec 2016

psychopathological disorders (Algeria, et al. 2007). Since the early 1980s, significant psychiatric epidemiologic surveys have been conducted on a broader geographic area. Most of the studies have employed structured diagnostic criteria and more specific psychopathological classifications like the ones in the Third or Fourth edition of the Diagnostic and Statistical Manual of Mental Disorders (DSM-III or -IV). Nonetheless, they have not generated consistent results for themonotonicity strength, or direction of the relationship between SES and mental disorder (Andrade et al. 2000).

We chose to carry out a systematic review so as assess the actual relationship between SES and mental disorder. Considering the methodological and geographic diversity of previous studies, we furthermore sought to illuminate on the methodological and contextual issues which might elucidate the variability of the results related to the SES-mental disorder.

\section{Methods}

A systematic review was employed in the analysis. The studies employed in this systematic review were chosen with a mix of processes to select the appropriate articles on the study.

\section{Search}

Search procedures involved keyword and search for particular authors by use the internet and a review of citations comprised in reviewed articles.

Keywords used were: Common mental disorders, depression, anxiety, education, income, deprivation, SES, socio-demographic, social correlates, socio-economic, socioeconomic, social class, psychiatric, psychopathology and mental.

The method in this systematic review encompassed correlational studies, SES studies and/or psychopathological studies. Being a comprehensive field, only research studies that investigated the relationship between SES and mental disorder were included.

Studies addressing common mental disorders (a mix of depression, mood disorders, anxiety) were included. Regarding SES, we retained studies providing a continuous individual level of stratification related to income, education, occupation, social class, or wealth (Krieger, Williams, \& Moss, 1997).

Three selection criteria were defined relative to date, setting, and population. Studies published after 1980 (consistent to the publication of the DSM-III) were selected. Selection was limited to works in which a community sample was used. These exclusion criteria prevented the biases related to referral or help-seeking behavior (Andrews, Henderson and Hall, 2001). The study was restricted the review to studies of adults (aged $\geq 15$ years); studies devoted to children or the elderly was excluded, mainly to reduce the confounding bias of poor physical well-being.

Interdisciplinary sources (psychology, psychiatry, medicine, sociology, and economics) were included. The search also followed up with a snowball search (Davis, 1997), as well as references from some papers relating to this topic.

The studies show that the SES-psychopathology relationship may be affected by numerous features associated to measurement and analysis. There are many tools in existence for the assessment of the psychiatric status of adults, and they can be divided into two main groups namely: psychiatric scales and diagnostic schedules (Murphy, 1995). Also, the strength of the relationship might differ based on the clinical category. Including all neurotic disorders, the way it was done in Kessler, McGonagle \& Zhao (1994), might result in stronger relationship because the definitions of substance disorder and anxiety, factors that might result in sharper socioeconomic slopes than mood disorders (Regier \& Farmer, 1993). On the other hand, the incorporation of all mood disorders might reduce the slope, since dysthymia might be distributed more equally among the socioeconomic strata than other mood disorders such as major depression (Wohforth, 1997). Then, the period of reference was also seen as a possible explanatory factor since the prevalence rate might be influenced more by the length of the episode for shorter reference periods. 


\section{Studies reviewed}

There have been two competing hypotheses in sociological inquiry that have delivered interpretations of the documented relationship between low socioeconomic status and common mental disorders. The selection hypothesis holds that common mental disorders hinders attainment, while the causation hypothesis holds that conditions of life related with low socioeconomic status distinctly hikes the risk of mental disorders. Using data from the longitudinal Dunedin Multidisciplinary Health and Development Study, Miech, Caspi, Moffitt, Wright and Silva (1999) examined selection and causation courses through the transition to early adulthood by way of exploring the reciprocal influence of mental disorders and educational attainment, a fundamental component of socioeconomic status. The Dunedin Study follows a group of people from 0 to 21 years of age and included psychiatric diagnoses for study participants at ages 15 and 21 employing the DSM criteria. Miech, Caspi, Moffitt, Wright and Silva (1999) focused on the four common mental disorders namely: anxiety, depression, attention deficit disorder, and anti-social disorder, and find a distinctive relationship with socioeconomic status for each of these disorders.

The study found that mental disorders among adolescents were more probably to be found among the youth in families with low socioeconomic status than would be predicted by chance alone. Furthermore, there were differences in the relationship between socioeconomic status and mental disorders when mental disorders were considered individually. Among common mental disorders, anxiety and depression, there were different associations with family's socioeconomic status. Anxiety was found to be disproportionately in families with lower SES as expected, however, depression was not. These findings are consistent with Kessler's (1994) findings that showed that SES is more strongly associated to anxiety than depression in the general population ages 15-54 (Kessler et al. 1994).

In another study by Arriola et. al. (2015), the study sought to examine the association between social support and physical and mental health among inmates and the probability that housing stability mediates this relationship among inmate living with HIV. The study included a cohort of HIV-infected inmates from 10 grantees funded, the study participants were needed to have been at the collaborating jails who were aged 18 years or above.

In a cross-sectional study data was obtained from 438 clients who participated in structured interviews. This study found a significant positive association between social support and both mental and physical well-being; while homelessness was related to lower mental wellbeing. Nevertheless, the study did not found any evidence of moderation. Additionally, the study demonstrated how important social support and economic considerations in the understanding well-being among HIV positive detainees (Arriola et al, 2015).

These studies show that accessible options to maintain health and wellbeing are limited in conditions of poverty and housing instability (Kushel et al., 2006; Weiser et al., 2009). Housing insecurity has been defined as "having difficulty paying rent, having frequent moves, living in overcrowded conditions, or doubling up with friends and relatives" (Kushel et al., 2006). To the point that housing uncertainty is an indicator of socioeconomic status, the Theory of Fundamental Causes elucidates why housing and health may be correlated (Link and Phelan, 1995; Phelan et al., 2004). This theory postulates that social factors such as social support and socioeconomic status presents access to essential resources such as money, electricity, prestige, and social connectedness) and thus have the possibility to serve as "fundamental causes" of a number of physical and mental health disorders.

Hudson (2005) study tested several hypotheses about the causal structure of the correlation between SES and mental disorder. He did this by analysis of a longitudinal statewide database on acute psychiatric hospitalization in Massachusetts between $1994-2000$ and census data. The modeling strategy employed techniques of structural equation modeling. This study found that SES impacted directly on levels of mental disorder and indirectly through the effect of economic hardship amongst the low and middle income groups (Hudson, 2005).

Agerbo, Nordentoft and Mortensen (2002) in attempting to estimate the risk of suicide among youths related to family as well as individual psychiatric and socioeconomic factors 
Texila International Journal of Psychology

Volume 1, Issue 2, Dec 2016

used a design population based nested case-control study. Data was collected from longitudinal Danish registers. It included 496 cases of youths aged 10-21 years who committed suicide in the period between 1981 and1997 in Denmark and 24800 controls matched for age, age and time. The main outcome measures all suicides in Denmark compared with controls; parents and siblings from population based registers; in-patient data from discharge registers of national hospitals; as well as socioeconomic data. The study found that parental factors related to an increased risk of suicide in youths were suicide hospitalization for a mental disorder, unemployment, low income, low level education and divorce, as well as mental disorder in siblings and mental disorder and low level education among the youths. The biggest risk factor was mental disorder among the youths. The impact of the parents' SES factors decreased after adjusting for a family history of mental disorder and of suicide (Agerbo, Nordentoft and Mortensen, 2002).

In another study (Weich and Lewis, 1998) to investigate whether poverty and unemployment increase the probability of or delayed recovery from common mental disorders as well as whether these relations could be explained by subjective financial stress. The study employed a prospective cohort study design in England, Wales, and Scotland with 7726 participants aged 16-75 residing in private households. The common mental disorders were evaluated by using the general health questionnaire (a self-assessed questionnaire of psychiatric morbidity). The study found that poverty and unemployment were linked with the maintenance yet not the onset of episodes of common mental disorders. The links between poverty and employment and maintenance of common mental disorders, were much smaller than those found in cross sectional studies. Furthermore, financial stress at baseline was independently linked with both onset and maintenance even after adjusting for objective indices of standard of living. Finally, both poverty and unemployment were found to increase the duration of episodes of common mental disorders however, not the probability of their onset. Then financial stress was found to be a better predictor of future mental disorder (Weich and Lewis, 1998).

In an attempt to test the hypothesis that persons in regions of Britain with the highest income inequality have higher prevalence levels of the common mental disorders, Weich, Lewis, and Jenkins (2001) employed a cross-sectional survey. The study recruited 8191 adults aged 16-75 living in private households based in England, Wales and Scotland. The prevalence of common mental disorders was measured by employing the General Health Questionnaire. The relationship between income inequality as well as prevalence of the common mental disorders were varied with individual income level. Amid individuals with the highest income levels, common mental disorders were more frequent in regions with higher income inequality. Furthermore, the reverse was true for those with the lowest income levels. Income inequality was linked to worse mental health amongst the most prosperous individuals (Weich, Lewis, and Jenkins, 2001).

To analyze the association between geographical income inequalities and common chronic medical conditions and mental disorders prevalence, and to match it with the association between family income and these health disorders (Roland and Roan, 2002). The study employed national household telephone survey between 1997-1998 among 60 metropolitan areas or economic areas in the United States.9585 adults were recruited in the study and participated in the community tracking.

The study found a strong continuous association between health and family income or education. However, there was no relation found between income inequality and depressive disorders and anxiety disorders or chronic medical problems prevalence, either in the whole population or among lower SES group. However, self-reported general health was significantly correlated with inequality at the level of the population, however, after adjustment this correlation disappeared for individual features. This study offers no evidence that income inequality poses as a major risk factor to common physical or mental disorders (Roland and Roan, 2002). 
In another study (Kahn, Wise, Kennedy, and Kawachi, 2000) to analyze the relationship of state income inequality and family income with the mental and physical health of women with young children. A cross sectional study design was employed. Individual family level data outcomes included income, and other sociodemographic covariates from a 1991 follow up survey of a birth cohort set in 1988 and income inequality at state level were calculated from the 1990 US census of each state income. Participants included nationally representative stratified random sample of 8060 women who had their babies in 1988 and contacted in 1991. The study results show that $19 \%$ women had depressive symptoms, and $7.5 \%$ had fair to poor health. Furthermore, women in the lowest fifth were more expected to report depressive symptoms and fair to poor health in contrast to women in the highest fifth of distribution of family income.

In comparison with low income women in low income inequality states, low income women in states from high income inequality showed a higher risk of depressive symptoms and fair to poor health. Overall, this study shows that high income inequality gives an increased risk of poor mental and physical health, predominantly among the poorest of women. Income inequality as well as family income are important for health among women (Kahn, Wise, Kennedy and Kawachi, 2000).

Araya, Rojas, Fritsch, Acuña and Lewis (2001) sought to determine the prevalence of common mental disorders including socio-demographic correlates among the adult population in Santiago, Chile. A cross-sectional survey in private households was conducted and a probabilistic sampling design was employed. Common mental disorders were assessed by means of the Clinical Interview Schedule-Revised (CIS-R). They found that of the 3870 participants interviewed 25\%were CIS-R cases while 13\% met criteria for an ICD-10 diagnosis. Low education, low social status, unemployment, female gender, separation and lone parenthood were associated with a higher common mental disorders prevalence (Araya, Rojas, Fritsch, Acuña and Lewis, 2001).

When determining the prevalence of psychiatric disorder, alternative diagnostic criteria were applied to a random sample of 576 women in an Edinburgh community (Surtees, Dean, Ingham, Kreitman, Millerand Sashidhara, 1983). Any diagnostic system was employed, resulted in significantly higher rates of disorder were among were divorced, widowed, cohabiting or separated women, working class and the unemployed; in the subgroup of women who met above conditions, up to $50 \%$ were found to satisfy the diagnostic criteria. The study shows that the prevalence rates can be explained as the factors effects of each demographic factor acting independently, no interaction effects being needed. Our results are discussed in relation to the findings of others, and in terms of the statistical issues involved (Surtees, Dean, Ingham, Kreitman, Millerand Sashidhara, 1983).

In a study in Australia, Korten and Henderson (2000) aimed at examining the distribution of common psychological symptoms as well as associated impairment in the Australian population. This arose from the fact that the mental health of populations can be denoted either by case prevalence rates or by symptom scales. Korten and Henderson (2000) hold that scales are advantageous in that they can be employed to identify sub-syndromal distress levels. The study employed a household representative sample of 10641 participants from the Australian population. They underwent the Composite International Diagnostic Interview. The study found that the Symptom scales demonstrated similar relationship with socioeconomic variables just as did diagnoses. Substantial impairment was related to symptom levels showing distress however, not reaching formal diagnoses levels of anxiety or depression (Korten and Henderson, 2000).

While most studies show that people at highest risk of suicide including those who are socially and economically underprivileged, are equally at high risk of being hospitalized with a mental disorders. In certain cases it seems that mental disorder is a determining factor on social position and suicide (Agerbo, Mortensen, Eriksson, Qin and Westergaard-Nielse, 2001). However, their study indicated that the significance of socioeconomic factors as risk factors for suicide was attenuated after adjustment for a history of mental disorder. They 
Texila International Journal of Psychology

Volume 1, Issue 2, Dec 2016

presentedfindingsfrom811casesofsuicideas well as 80787 matched control subjects from a population based study whose aim to gain further insight in to the relationship between social position and mental disorder (Agerbo, Mortensen, Eriksson, Qin and Westergaard-Nielse, 2001).

With regard to comparing groups in two group from economically different country, Hollifield, Katon, Spain and Pule (1990) compared data from adults in a village in Lesotho, and data from a large epidemiological study in the United States. Participants were interviewed utilizing the same research instrument to find out the community prevalence of panic disorder, major depression, and generalized anxiety disorder. The prevalence data of the two were then compared with data. They found a significantly higher prevalence rates of all three diagnoses in Lesotho in comparison to the United States. Data from the two populations showed that women were at an increased risk of the three disorders, even though statistical significance was not established for depression. The majority of participants (77\%) who had panic attack episodes reported that they had sought help for these symptoms, with the majority seeking help from Western-trained doctors. The association between explanatory models and help-seeking behavior were explored among people who had had panic attacks. $40 \%$ Less than participants with generalized anxiety disorder reported having sought help. The findings were attributed to difference in SES (Hollifield, Katon, Spain and Pule, 1990).

In another studying the investigating the association between SES and common mental disorder Stewart-Brown, Samaraweera, Taggart, Kandala and Stranges (2015) studied whether the socioeconomic correlates of mental well-being match those for mental disorder. The study was conducted among 13983 participants of the 2010 and 2011 Health Surveys for England. The study found that low mental well-being matched those for mental disorder, however, not those of high mental well-being, demonstrating that the SES factors linked with positive mental health are different from those linked with mental illness (Stewart-Brown, Samaraweera, Taggart, Kandala and Stranges, 2015).

\section{Discussion}

The above reviewed studies have found a relationship between SES, income inequality, educational level, gender and mental health or disorder. Furthermore, ongoing efforts to understand the causal issues involved in the correlation between socioeconomic status and mental disorder show that the hypothesis of a recursive or interactive association might be the most plausible, at least with the mental disorder. Some of the factor involved in this relationship could include mental health costs of economic policies, allocation mental health resources, and the employment of this knowledge-base in service planning and delivery.

It is apparent that there is a strong social gradient in health, as measured by the prevalence of general medical conditions and common mental health disorders, by income and education. Decades after the Dohrenwend and Dohrenwend (1969) milestone review, SES seems continue to correlate with common disorder. Low SES does seem to increase the risk of episode onset as well as the risk for persistence of common mental disorders. This association is not restricted to the lower SES group but continues throughout the whole social stratum.

The king of this relationship is not straightforward. Concerning the direction of this association for common mental disorders, the studies more consistently show the argument that causation i.e. low SES increases risk of common mental disorders - has the edge over selection i.e. depression hinders social movement (Dohrenwend, et al 1992; Kessler, 1995; Johnson, 1999).

The processes associating SES and common mental disorders can be divide roughly into two groups: stress and strain (Thoits, 1999). The stress theory posits that personal resources, including coping style, mastery, self-esteem and locus of control, cushion the effect of stress on common mental disorders and that people in higher-SES groups are gifted with such resources (Brown, 1984 \& Wheaton, 1980). The strain theory addresses the influence of community features such as social welfare, values, social cohesion, public health policy and infrastructure (Thoits, 1999; Lomas, 1998; Robert and House, 2000). This outlineis based on 
between-country differences in socioeconomic health inequalities observed for subjective health (Van Doorslaer, 1997; Hollifield, Katon, Spain and Pule, 1990) or cause-specific mortality (Kunst, Groenhof and Mackenbach, 1998). However, the evidence for such contextual effects on mental disorders is inconsistent (Duncan, Jones and Moon, 1995; Driessen, Gunther and Van Os, 199). Studies have shown that individual income and regional inequalities in income are interlinked in influencing the level of mental disorder (Weich, Lewis and Jenkins, 2001; Roland and Roan, 2002; Kahn, Kennedy and Kawachi, 2000). Furthermore, the relationship between socioeconomic inequalities and common mental disorder differs in different regions and nations.

This review could have been affected by limitations related to confounding bias, and publication bias. For example, gender and age could be confounding factors in the SEScommon mental disorder relationship. For instance it is well known that women have a higher prevalence of some common mental disorders such as depression and lower SES, and younger people have a higher risk of being lower SES groups, therefore, ignoring gender will intensify the SES gradient. In addition, ignoring age is likely to suppress the gradient.

Physical disease might also provide another possible confounding factor that is rarely considered in mental health epidemiology (Dohrenwend, 1998). Very few of the studies reviewed included analysis of physical health. However, studies (Hippisley-Cox, Fielding, Pringl, 1998) show that a relationship exists between mental disorder and physical diseases such as cancer as well as cardiovascular disorders and another relationship between SES and physical diseases exists. However, a study by Lynch, Kaplan and Shema (1997) proposes that the general effect of physical disease on the SES-common mental disorder relationship is small.

Furthermore, certain significant mental health epidemiologic studies did not consider the problem of the SES distribution of common mental disorder (Offord, Boyle and Campbell, 1996; Wittchen, Essau and von Zerssen, 1992). A later cross-national review showed that education was associated to mental health status in Ontario however, not in Munich (Andrade, et al. 2000). Also an availability bias is present, predominantly in to developing countries. Studies like these may not even be published in peer-reviewed English-language journals. Taking a recent cross-national review of seven countries as an example (Andrade, et al. 2000), some studies from developing countries were not published in peer-reviewed journals.

\section{Conclusion}

Regardless of these, there is convincing evidence of inequalities in common mental disorders favoring the higher SES groups. This should lead to informing planning and implementation of health programs. The review show that one strategy would be to put emphasis on reducing the chronicity of depression among people in the lower socioeconomic strata.

\section{References}

[1]. Agerbo, E., Mortensen, P. B., Eriksson, T., Qin, P. and Westergaard-Nielsen, N. (2001). Risk of suicide in relation to income level in people admitted to hospital with mental illness: nested casecontrol study. Lancet, 322, 334 - 335.

[2]. Agerbo, E., Nordentoft, M., and Mortensen. P. B. (2002). Familial, psychiatric, and socioeconomic risk factors for suicide in young people: nested case-control study. British Medical Journal, 325(7355), 74.

[3]. Alegria, M., Bijl, R.V., Lin, E., Walters, E.E. and Kessler, RC. (2000). Income differences in persons seeking outpatient treatment for mental disorders: a comparison of the United States with Ontario and the Netherlands. Achieves of General Psychiatry, 57:383-91.

[4]. Andrade, L., Caraveo-Anduaga, J.J., Berglund, P., et al. (2000). Cross-national comparisons of the prevalences and correlates of mental disorders. Bull World Health Organization, 78, 413-26. 
Texila International Journal of Psychology

Volume 1, Issue 2, Dec 2016

[5]. Andrews, G., Henderson, S. and Hall, W. (2001). Prevalence, comorbidity, disability and service utilisation-overview of the Australian National Mental Health Survey. British Journal of Psychiatry, $178,145-53$.

[6]. Anthony, J.C., Eaton, W.W. \& Henderson, A.S. (1995). Introduction: psychiatric epidemiology. Epidemiological Review, 17:1-8.

[7]. Araya, R., Rojas, G., Fritsch, J., et al. (2001). Common mental disorders in Santiago, Chile: prevalence and socio-demographic correlates. British Journal of Psychiatry, 178, 228-33.

[8]. Arriola1, K. J., Spaulding, A. C., Booker, C. A., Williams, C., Avery, A., Porter, N. J., Jordan, A. O., Loewenthal, H. and Frew, P. M. (2015). Understanding the relationship between social support and physical and mental well-being among jail detainees living with HIV. Journal of Health Psychology, 20(1), 3-12

[9]. Bebbington, P., Brugha, T., Meltzer, H, et al. (2000). Psychiatric disorder and dysfunction in the UK National Survey of Psychiatric Morbidity. Social Psychiatry and Psychiatric Epidemiology, 35, 191-197.

[10]. Brown, G. and Harris, T. (1984). Social origins of depression: a study of psychiatric disorder in women. London, United Kingdom: Tavistock Publications.

[11]. Davis M. (1997). Scientific papers and presentations. San Diego, CA: Academic Press.

[12]. Dohrenwend, B.P., (1998). A psychosocial perspective on the past and future of psychiatric epidemiology. American Journal of Epidemiology, 147, 222-31.

[13]. Dohrenwend, B.P. and Dohrenwend, B.S. (1969). Social status and psychological disorder: a causal inquiry. New York, NY: John Wiley and Sons, Inc.

[14]. Dohrenwend, B.P, Levav, I., Shrout, P.E., et al. (1992). Socioeconomic status and psychiatric disorders: the causation-selection issue. Science, 255, 946-52.

[15]. Driessen, G., Gunther, N. and Van Os J. (1998). Shared social environment and psychiatric disorder: a multilevel analysis of individual and ecological effects. Social Psychiatry and Psychiatric Epidemiology, 33, 606-12.

[16]. Duncan, C., Jones, K. and Moon, G. (1995). Psychiatric morbidity: a multilevel approach to regional variations in the UK. Journal of Epidemiology and Community Health, 49, 290-5.

[17]. Hippisley-Cox, J., Fielding, K. and Pringle, M. (1998). Depression as a risk factor for ischaemic heart disease in men: population based case-control study. British Medical Journal, 316:1714-19.

[18]. Hollifield, M., Katon, W., Pule, L, et. al. (1990). Anxiety and depression in a village in Lesotho, Africa: a comparison with the United States. British Journal of Psychiatry, 156, 343-50.

[19]. Holzer, C.E., Shea, B.M., Swanson, J.W, et al. (1986). The increased risk for specific psychiatric disorders among persons of low socioeconomic status. American Journal of Social Psychiatry, 6, 25971.

[20]. Hudson, C. G. (2005). Socioeconomic Status and Mental Illness: Tests of the Social Causation and Selection Hypotheses. American Journal of Orthopsychiatry, 75, (1), 3-18. DOI: 10.1037/00029432.75.1.3

[21]. Johnson, J.G., Cohen, P., Dohrenwend, B.P., et al. (1999). A longitudinal investigation of social causation and social selection processes involved in the association between socioeconomic status and psychiatric disorders. Journal of Abnormal Psychology, 108, 490-9.

[22]. Lomas, J. (1998). Social capital and health: implications for public health and epidemiology. Social Science and Medicine, 47, 1181-8.

[23]. Lynch, J.W., Kaplan, G.A. and Shema, S.J. (1997). Cumulative impact of sustained economic hardship on physical, cognitive, psychological, and social functioning. The New England Journal of Medicine, 337, 1889-95.

[24]. Kahn, P. H. Wise, B., Kennedy, P. and Kawachi, K. (2000). State income inequality, household income, and maternal mental and physical health: cross sectional national survey. British Medical Journal, 321, 1311 - 1315

[25]. Katz, S.J., Kessler, R.C., Frank, R.G., et al. (1997). Mental health care use, morbidity, and socioeconomic status in the United States and Ontario. Inquiry, 34, 38-49.

[26]. Kessler, R.C., Foster, C.L., Saunders, W.B., et al. (1995). Social consequences of psychiatric disorders. I. Educational attainment. American Journal of Psychiatry, 152, 1026-32. 
[27]. Kessler, R. C., McGonagle, K.A. Zhao, S., Nelson, C.B. Hughes, M., Eshleman, S., Wittchen, H. U. and Kendler, K.S. (1994). "Lifetime and 12-month Prevalence of DSM-III-R Psychiatric Disorders in the United States: Results from the National Comorbidity Study." Archives of General Psychiatry, 51, 8-19.

[28]. Korten, A. and Henderson, S. (2000). The Australian National Survey of Mental Health and Well-Being — common psychological symptoms and disablement. British Journal of Psychiatry, 177, 325-30.

[29]. Krieger, N., Williams, D.R., \& Moss, N.E. (1997). Measuring social class in US public health research: concepts, methodologies, and guidelines. Annual Review of Public Health, 18, 341-78.

[30]. Kushel, M.B., Gupta, R., Gee, L. and Haas, J.S. (2006). Housing instability and food insecurity as barriers to health care among low-income Americans. Journal of General Internal Medicine, 21(1), 7177

[31]. Kunst, A.E., Groenhof, F. and Mackenbach, J.P. (1998). Occupational class and cause specific mortality in middle aged men in 11 European countries: comparison of population based studies. British Medical Journal, 316, 1636-41.

[32]. Phelan, J.C., Link, B.G., Diez-Roux. A., Kawachi, I. and Levin, B. (2004). "Fundamental causes" of social inequalities in mortality: A test of the theory. Journal of Health and Social Behavior, 45(3), 265-285

[33]. Phelan, J.C., Link, B.G and Tehranifar, P. (2010). "Social conditions as fundamental causes of health inequalities: Theory, evidence, and policy implications". Journal of Health and Social Behavior. 51, S28-S40. Doi:10.1177/0022146510383498

[34]. Miech, R.A., Caspi, A., Moffitt, T.E., Wright, B.R. and Silva, P.A. (1999). Low socioeconomic status and mental disorders: A longitudinal study of selection and causation during young adulthood. American Journal of Sociology, 104(104), 1096-1131.

[35]. Murphy, J.M. (1995). Diagnostic schedules and rating scales in adult psychiatry. In: Tsuang M, Tohen M, Zahner G, eds. Textbook in psychiatric epidemiology. New York, NY: John Wiley and Sons, Inc.

[36]. Offord, D.R., Boyle, M.H., Campbell, D., et al. (1996). One-year prevalence of psychiatric disorder in Ontarians 15 to 64 years of age. The Canadian Journal of Psychiatry, 41, 559-63.

[37]. Regier, D.A. and Farmer, R.E. (1993). One-month prevalence of mental disorders in the United States and sociodemographic characteristics: The Epidemiologic Catchment Area Study. Acta Psychiatrica Scandinavica, 88, 35-47.

[38]. Robert, S. and House, J. (2000). Socioeconomic inequalities in health: integrating individual, community and societal level theory and research. In: Albrecht GL, Fitzpatrick R, Scrimshaw S, eds. The handbook of social studies in health and medicine. Thousand Oaks, CA: Sage Publications.

[39]. Roland, S. and Roan, G. C. (2002). Relations of income inequality and family income to chronic medical conditions and mental health disorders: national survey. British Medical Journal, 324, 20

[40]. Stansfeld, S.A. and Marmot, M.G. (1992). Social class and minor psychiatric disorder in British civil servants: a validated screening survey using the General Health Questionnaire. Psychological Medicine, 22, 739-49.

[41]. Stewart-Brown, S., Samaraweera, P.C., Taggart, F., Kandala, N.B. and Stranges, S. (2015). Socioeconomic gradients and mental health. The British Journal of Psychiatry, 206, 461-465. Doi: 10.1192/bjp.bp.114.147280

[42]. Surtees, P. G., Dean, C., Ingham, J.G., Kreitman, N.B., Mcc.Millerand, P. and Sashidharan. S. P. (1983). Psychiatric Disorder in Women from an Edinburgh Community: Associations with Demographic Factors. British Journal of Psychiatry, 142, 238 - 246

[43]. Thoits, P. (1999). Sociological approaches of mental illness. In: Horwitz AV, Scheid TL, eds. A handbook for the study of mental health: social contexts, theories, and systems. Cambridge, United Kingdom: Cambridge University Press.

[44]. Turner R.J. and Lloyd D.A. (1999). The stress process and the social distribution of depression. Journal of Health and Social Behavior, 40, 374-404.

[45]. Van Doorslaer, E., Wagstaff, A., Bleichchrodt, H., et al. (1997). Income-related inequalities in health: some international comparisons. Journal of Health Economics, 16, 93-112 
Texila International Journal of Psychology

Volume 1, Issue 2, Dec 2016

[46]. Weich, S. and Lewis, G. (1998). Poverty, unemployment, and common mental disorders: population based cohort study. British Medical Journal, 317:115-19.

[47]. Weich, S., Lewis, G. and Jenkins, S.P. (2001). Income inequality and the prevalence of common mental disorders in Britain. British Journal of Psychiatry, 178:222-7.

[48]. Wheaton, B. (1980). The sociogenesis of psychological disorder: an attributional theory. Journal of Health and Social Behavior, 21, 100-24.

[49]. Wittchen, H.U., Essau, C.A., von Zerssen. D., et al. (1992). Lifetime and six-month prevalence of mental disorders in the Munich Follow-up Study. European Archives of Psychiatry and Clinical Neuroscience, 241:247-58.

[50]. Wohlfarth, T. (1997). Socioeconomic inequality and psychopathology: are socioeconomic status and social class interchangeable? Social Science \& Medicine, 45, 399-410. 